\title{
Native Tongue by Mojo Juju
}

\section{Paul Murchison}

University of Technology Sydney, Faculty of Arts and Social Sciences, PO Box 123, Ultimo NSW 2007, Australia.paul.k.murchison@student.uts.edu.au

The following is a review of the song and accompanying video clip 'Native Tongue' by Mojo Juju (Luzuriaga 2018); a queer artist of mixed Indigenous Australian, white Australian and Filipino ethnicities. The song tells of her struggles with this identity in the Australian context and the video clip uses striking imagery to accompany this story. Both the song and the video successfully use elements of hip-hop and Aboriginal corroboree, combined with glitchy effects to communicate a disconnect between the artist and her confusing identity.

The song's lyrical content initially tells us about Mojo's inability to speak the same language that her father first learnt. She then establishes that her father is Filipino, and her great grandfather is Aboriginal. The repeated lines 'I don't know where I belong' create the theme of disconnect to place and identity, one that is common in stories of contemporary Indigenous Australians (Luzuriaga 2018). The song combines elements of the blues with electronica and hip-hop, the latter of which is crucial to the Indigenous story arc throughout the video.

The video is a single shot for the duration of the clip with Mojo taking up the centre of the frame for the entirety of the video. It takes place in an Australian rural landscape and features dancers from the Aboriginal dance troupe Djuki Mala. The clip also features many glitched video effects throughout the clip that match the glitchy style of production of the audio. This serves, as well to push the narrative of feeling out of place described in the lyrics.

The video begins with Mojo walking towards the camera in a rural field, surrounded by long grass that is dry and arid. This is a typical eastern Australian inland landscape and an excellent choice in setting for explaining the disconnect Mojo feels to the land she's standing in. She mentions in the first verse that her 'great granddaddy was Wiradjuri' - Indigenous Australian Aboriginals from central New South Wales - which links to identity and place (Luzuriaga 2018). Mojo wears a fur coat and gold chains over black clothes. The chorus of the song repeats the lyrics, 'I don't know where I belong', her clothes suggesting that she 
doesn't belong in this part of Australia, where she's supposedly 'from' (Luzuriaga 2018). The next line of the song tells us that her father is Filipino. Within this identity, there's a disconnect between being both Indigenous and first-generation immigrant. Australia has a contentious history regarding mixed race and 'half-caste' Aboriginals (Neville 1947).

Mojo is flanked by three indigenous dancers from the dance group Djuki Mala wearing striking red jumpsuits and bright white sneakers. Their dancing style is contemporary hip-hop blended with traditional Aboriginal dance, borrowed from Aboriginal corroboree. MC Wire, in 2003, spoke of the parallels between hip-hop culture and the corroboree; song and dance to teach history and share culture (Mitchell 2006). There are strong links between Aboriginal history and American black history too and in particular the civil rights movement in the USA and its influence on civil rights for Aboriginal Australians (Maynard 2005). This is, of course, relevant because of the origins of hip-hop taking place in America and created by African Americans, and that hip-hop has been a soap-box of sorts for race politics. Mojo uses the history of hip-hop to help tell her own story; it's not merely an aesthetic musical choice.

Lyrically, this song is not cryptic. There's no hidden meaning, but it is powerful poetry because of this. The opening line 'I don't speak my father's native tongue' is immediately jarring given that 'Native Tongue' is the title of the song - instead of the song being about her native tongue, it's about her disconnect with what it means to be mixed race. The repetition of the line 'I don't know where I belong' and the melody of the song are stylistically the blues (Luzuriaga 2018). Combined with the chanting from The Pasefika Vitoria Choir throughout the song, the style and aesthetic of the voice is front and centre throughout the song. Later, when the percussive elements are introduced, they sound unsettling and unnatural due to their glitched style of production. It's at this point where all of these elements intersect; you have traditional American blues aesthetics mixed with hip hop, also from America. There's the intersect between American history of civil rights and the parallels with black rights in Australia, and then there is the disconnect of those who are descendants of the Stolen Generations trying to piece together their identity in modern Australia (Morgan \& Warren 2011). All of these themes are a careful balancing act that Mojo and the video producers execute expertly.

The glitchy effects throughout the video, both visual and auditory, serve to push the narrative that things are unnatural in their place. A glitch is an unnatural element to a digital format, and its deliberate presence in this video and song further emphasises the lyrics 'I don't know where I belong' (Luzuriaga 2018). This glitchiness is central to the feeling Mojo is trying to convey in the lyric 'but you make me feel so ill at ease (Luzuriaga 2018)'.

At the end of the clip, as Mojo and Djuki Mala turn to walk away, Djuki Mala all turn back to the camera and wipe white face paint over their foreheads. As they walk away, they dance a traditional Aboriginal dance emphasising this idea of corroboree in hip-hop. 
Where this song differentiates itself from other Indigenous music is that it's not directly political. It is tackling issues of identity and belonging and how that relates to race and indigeneity, but it's not an attack on policy or a reflection of the past. If anything, it's about the here and now, which makes it the most relevant it can possibly be.

\section{References}

Luzuriaga, M.R.d. 2018, 'MOJO JUJU - NATIVE TONGUE Featuring The Pasefika Vitoria Choir (Official Music Video)', <https://www.youtube.com/watch?v=JLQ4by3lUJo>.

Maynard, J. 2005, 'In the interests of our people': the influence of Garveyism on the rise of Australian Aboriginal political activism', Aboriginal History Journal, vol. 29, pp. 1-22.

Mitchell, T. 2006, 'Blackfellas rapping, breaking and writing a short history of Aboriginal hip hop', Aboriginal History Journal, vol. 30.

Morgan, G. \& Warren, A. 2011, 'Aboriginal youth, hip hop and the politics of identification', Ethnic and Racial Studies, vol. 34, no. 6, pp. 925-47.

Neville, A.O. 1947, Australia's Coloured Minority, Currawong Publishing Co. Pty. Ltd., Sydney. 